\title{
De corpo e alma
}

\author{
Guilherme Werlang \\ Departamento de Humanidades e Saúde - UFF
}

RESUMO: As noçōes de "corpo" e "alma", dentro do universo dual dos Marubo do sudoeste da Amazônia, aproximam-se de outras contribuições deste volume, primeiro, em vista da presente preocupação, em perspectiva universalizante, com questões epistemológicas na Amazônia; segundo, em vista da relevância, ora bem perene, da ontologia indígena (aqui mais enquanto "presentificação" que "investigação" ou "relato" das origens do cosmos e de todas as formas de ser que nele se dá) para com o conhecimento, de tendência particularizante, da performance dum ethos cognitivo.

PALAVRAS-CHAVE: Amazônia, Brasil, Marubo, pessoa, cognição, ontologias indígenas.

Uma vez que o pensamento é inseparável da ação e da motivação, não estamos lidando tanto com "lógicas" ou racionalidades diferentes, e sim com modos totais de ser, de inventar o eu e a sociedade. (Wagner, 1981, p. 117)

[...] os Piaroa não costumam contrapor, da maneira como fazemos, o pensar e o agir. Não podemos usar nossa glosa de "mente" e "corpo" para apreender seu modo de entender esta distinção. Eles, na verdade, não têm palavra para "corpo". (Overing, 1996, p. 14) 
Este ensaio coloca em questão a plausibilidade das noções "corpo" e "alma" desde dentro do universo dual dos Marubo do sudoeste da Amazônia. ${ }^{1}$ Há uma dupla implicação da questão na "familiaridade com as epistemologias e ontologias de outras culturas" (Overing, 1985, p. 7). Uma, em vista do presente interesse - como este volume tão bem ilustra -, na perspectiva pós-estruturalista sobre questóes epistemológicas na Amazônia. Outra, em vista do entendimento - mais de vinte anos após a publicação de Reason and Morality - da ontologia indígena como "presentificação", aquém e além de "investigação" ou "relato", das origens do cosmos e de todos os seres que há nele, visando ao entendimento da performance dum ethos cognitivo.

Está clara a correspondência dessas duas visões àquelas que neste volume expõe Dan Rosengren. Ao leitor serão elas familiares, levando-o no que virá a seguir a suas conclusóes próprias. Enquanto ex-aluno de Joanna, minhas próprias conclusões propõem um passo adiante de suas antigas preocupaçôes, passo que parece com ela condizer: partir duma "atenção ao linguajar comum, à pragmática dos atos de fala comuns", para chegar à forma, poética ou o que for, com a qual "os outros falam de seus mundos sociais" (Overing, 1985, p. 7-19). ${ }^{2}$

O que segue é uma série de trechos etnográficos que até agora ficaram de fora de meus escritos anteriores sobre a mítica dos Marubo, povos indígenas do Alto Vale do Javari (Amazonas, Brasil). Todos esses escritos, meus ou de outros autores, até o momento configuram análises de alguns poucos fragmentos ou aspectos da mitologia dos Marubo ver Melatti $(1985,1986,1989)$ e Werlang $(2002,2003)$. Um cômputo exaustivo ainda está para ser feito. ${ }^{3}$ Minhas próprias explicações tiveram uma intenção musical. Os mitos dos Marubo, em sua língua-mãe, são chamados saiti - o que vim a traduzir como "cantos-mito". 
Como Fernando Santos-Granero nos faz lembrar neste volume, a psicofisiologia aristotélica concebe perceptos que afetam nossos corpos antes mesmo que nossas almas os cogitem. ${ }^{4}$ Tendo-os agora já em mente, meus ouvidos percebem saiti como o mito no canto, como o canto no mito. Aqui, assim como ocorre com os Yanesha, a psicofisiologia marubo dialoga com Aristóteles e Platão. Pois os Marubo encenam, no saiti, um encontro entre eles mesmos, entre suas próprias almas como constitutivas do corpo, algo bem estranho àquelas hierarquias cognitivas. Por ser uma festa intercomunitária, saiti é um evento relevante, ainda que freqüente, em suas vidas sociais. Por ser música, saiti é mais do que um mero "discurso acerca de 'deuses, semideuses, demônios, heróis e habitantes do Hades", nos dizeres de Platão; é sobretudo "pura expressão do encontro de homens com deuses, num mundo que é, para cada encontro, o cenário em que o mesmo decorre" (Sousa, 1973, p. 118). Um encontro que envolve corpos e almas, humanidade e animalidade.

A ontologia marubo é performática porque é saiti. Ela tem tanto a ver com "deuses" como com "corpos" e "almas", porquanto tem menos a ver com epistemologia do que nossa própria ontologia. ${ }^{5}$ Tem mais a ver com religião e ritual, como é o caso da cosmologia entre os pré-socráticos, do que com Platão e Aristóteles. E tal está tão longe de ser uma declaração positivista quanto de ser um lugar-comum (cf. Sousa, 1975).

\section{Mito-música saiti}

O que vem a seguir é uma breve suma de alguns saiti. Como síntese do proposto acima, os extensos textos e sons de cada qual serão postos de lado. Em vez, segue uma lista dos cinco saiti em questão, com suas células musicais correspondentes: 
Mokanawa Wenia: "a emergência dos povos acre-selvagens":

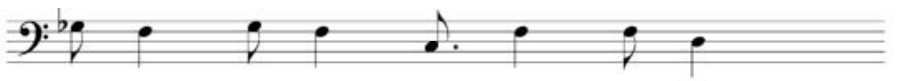

Shane Memi Yõsha: "a velha Memi verde-azul":"

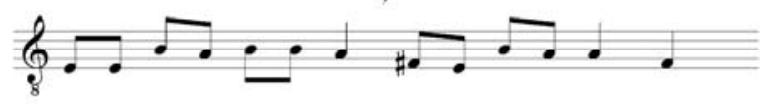

Vausa Tiun: "o norco-nueixada nrototínico":

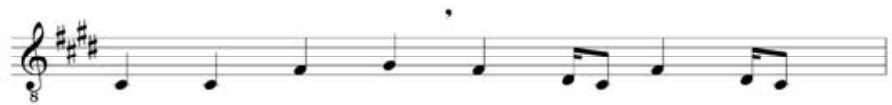

Teté Teka: "o tiro no gavião":

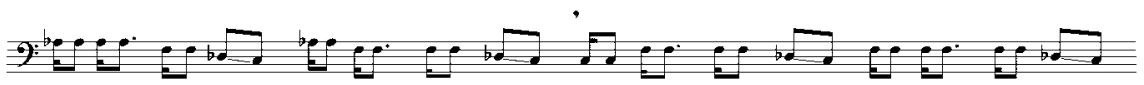

Vei Vai Yoya: "o guia do caminho das transformações perigosas":

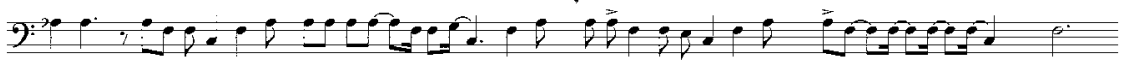

Esses saiti apresentam algum tipo de dualismo, por conta tanto de sua dualidade intrínseca na qualidade de cantos-mito - narrativas de mitos em contraste com entonações de canto - quanto de sua musicalidade, justo a qualidade poética que ficará de fora, à exceção das células musicais que, para cada saiti, os pentagramas acima resumem. Repare que cada célula reiterativa - saiti é música minimalista ao máximo apresenta duas seções contrastantes - uma característica que, além de ser por si só evidente, a distribuição dos versos apenas enfatiza (ver Werlang, 2001). 
Esses saiti tratam de alguma forma de seres humanos e animais. É com base nesse tratamento que poderemos inferir um dualismo indígena e a aplicabilidade, ou inaplicabilidade, da dualidade corpo-alma em nosso trato com os Marubo. O leitor decidirá até que ponto tal idioma é aplicável ao falar sobre esses povos - ou, ainda, sobre a mito-música saiti.

\section{Dualismo mítico-musical}

A precedente dialética dual, na forma dos saiti, nem bem se refere exclusivamente à dimensão musical dos cantos-mito nem, tão-somente, ao caráter tonal das palavras nos cantos acima. O conspícuo caráter formal do gênero vocal saiti fica também aparente quando se toma as palavras em sua dimensão "atonal", na fonética silenciosa, no nível verbal: em estrofes, rimas, artifícios poéticos. A recorrência de certas fórmulas verbais é uma característica presente em todos os saiti. No mais das vezes, a estrutura verbal maior dos cantos-mito saiti fica visível no papel, na bidimensionalidade visual de sua transposição verbal. Ainda, nalguns cantos-mito, a divisão aparente num nível mais abrangente do que o da célula musical revela algo mais do que simples blocos semânticos ou estágios narrativos; a expressão mais alta se encontra nos grupamentos temáticos de vários versos, para além da dimensão celular de sua entoação, embora tentando igualá-la: estrofes, rimas, artifícios poéticos. No mais das vezes, tal redunda em dualismo formal.

Tome o saiti de Shane Memi Yõsha, em que a narrativa linear em sua dimensão mais ampla é dupla: alguém narra a história e então a "história", a "velha" Shane Memi, "azul-verde" Memi, "narra a si mesma", repetindo o primeiro trecho quase que palavra por palavra. Isso confere por si só uma unidade geral aos 180 versos e às células isomórficas cor- 
respondentes desse saiti. Daí o verso conclusivo, a "chave de ouro" desse discurso verbal, reafirmar o ponto de vista secundário ou, com efeito, o ponto de vista de um terceiro posto no decorrer da narrativa, por meio de uma fórmula recorrente nos cantos-mito: a ikiao i, "assim falou" Shane Memi Yõsha. ${ }^{7}$ A centralidade dessa personagem principal está em sua voz influente na narrativa, mais do que em ser protagonista. Os músicos-narradores dos saiti silenciariam a própria influência por meio do som de suas vozes.

Nas festas, os cantores sempre respondem a um líder. Esse líder-cantor, yoya, entoa um verso que um coro repete ipsis litteris; e assim continua, um após outro, sempre dentro da mesma célula musical. Em todo saiti, cada verso corresponde a uma das respectivas células acima: para $n$ versos, para cada saiti, uma única e mesma célula musical. O "puxador" (líder-cantor) vai construindo assim a narrativa, enquanto os cantores respondentes caminham aos pares, em círculo, "viajando" - como dizem.

Além da coreografia, o conteúdo verbal desse saiti pode derramar mais luz sobre a jornada musical da velha Shane Memi Yôsha. Pode desviar nosso olhar para os rumos indígenas... assim como pode nos levar a cometer disparates essencialistas. Comparações e generalizações são um risco que pode valer a pena, conquanto nos devolva à dialética sônica saiti de fonemas verbais e tom musical, e a suas hierarquias formais.

Como acontece com outras personagens míticas na Amazônia (por exemplo, Stolze Lima, 1999, p. 43), Shane Memi sofre um arrebatamento, fruto da tentativa desastrosa de obter o fígado duma anta - por meio do ânus do animal a dormir. A anta acorda e sai loucamente, disparando numa rota toponímica e etnonímica, arrastando-a para cima e para baixo, num passeio por céus e terra. Quando seus filhos a encontram, mal a reconhecem: Shane Memi se tornara quase que uma anta, presa na armadilha que eles mesmos armaram. 
Se os relatos dos Marubo e de outros povos amazônicos fossem variações sobre um tema mítico, um silogismo estrutural nos faria acreditar que os primeiros cogitam relações com presas de caça semelhantes às que os últimos mantêm com animais em geral.

Com efeito, como nas histórias contadas por Rosengren (neste volume), Shane Memi sofre por ter relações predatórias impróprias com uma anta, um comportamento desviante que resulta numa identificação excessiva com o animal. Conforme ocorre noutros casos, o protagonista mítico compartilha com o animal do mesmo alimento ou gera crias dele. Nesse como noutros casos, a identificação substancial com o animal desaparece quando um terceiro consangüíneo da espécie humana apanha o protagonista com armadilhas ou o acerta com flechas. O destino absurdo da velha transgressora, arrastada por um cu preênsil, é semelhante a uma viagem xamânica: promove o acesso a um reino celestial ou à transmutação do corpo. A caçada bem-sucedida põe fim ao intercurso pseudopredatório, o qual identifica presa e predador aquém, ou para além, do ato predatório.

Porém, para além dos silogismos analógicos, precisamos voltar nossa atenção aos paradoxos literais, locais. Pois estes se afiguram como aspecto mais comparativo dos cantos-mito saiti do que meros traços comuns presentes por toda a região. Alheia a formulações universalizantes e grandiosas, esta postura analítica deve deixar dar vazão à síntese etnográfica. Voltemos, então, à etnografia. Pois a mesma identificação entre ser humano e animal que o mito postula e nega está latente em sua ontologia musical. 


\section{Pessoas e povos, espíritos e duplos}

Os Marubo pertencem à família lingüística pano - as linhas que seguem devem soar familiares aos panólogos.

Segundo os Marubo, para cada yora - uma autodenominação sem especificidade étnica -, existe uma série de "almas" autoconstitutivas. Para cada "corpo", existem várias almas que, em sua integração, definem o conceito de humanidade implícito em yora. Para cada yora humano, existe a "alma do lado esquerdo" - mechmiri vaká, que é um potencial yochi -, um "duplo-animal" e agente causador de doenças, e existe, é claro, a "alma do lado direito" - mekiri vaká, um potencial "espírito" ou yové.

O yochi é o candidato mais conveniente para a hipóstase do mal nas pregaçōes dos missionários. ${ }^{8}$ Os missionários traduzem yochi como bicho, no senso regional de "animal" ou "fera". De fato, ele emana do intercurso irregular com animais durante a caça: condutas imorais entre o predador humano e sua presa, como a história anterior ilustra, libera o nocivo yochi . Além do mais, esse "duplo" se identifica com excreções e cadáveres, com tudo que degenera, tudo que já passou. Em termos psicológicos, é a contrapartida material das reminiscências que impregnam os objetos pessoais e a moradia daqueles que já morreram. ${ }^{9}$ Os yochi têm preferência por florestas e pela solidão - donde, mais uma vez, minha glosa.

A despeito de minha glosa e da simetria tautológica da anatomia indígena, o espírito yové é menos receptivo ao maniqueísmo missionário. Em termos fisiológicos, é uma capacidade alcançável, uma habilidade inerente à voz e visão humanas - e, por conseguinte, aos pensamentos humanos. Um xamã ouviu-me cantando e viu yové - ele disse ter visto desenhos na minha garganta, kene mônti. Ouvir "beleza" - roaka, ele disse enquanto ouvia - é visão do espírito. 
Revista de Antropologia, São Paulo, USP, 2006, v. 49 no 1.

À visão, o yové se manifesta mais como latência do que como atualidade. Quando a manifestação é outra, é como performance musical. Além da associação sinestésica de desenho e som, tão familiar aos panólogos (por exemplo, Gebhart-Sayer, 1985), os yové se manifestam como homúnculos que habitam as copas das árvores na floresta. Tal como gnomos ou fadas, eles constituem uma realidade "sobrenatural" que apenas os xamãs podem ver. Inversamente, a percepção dos xamãs é coerente com a forma como eles se percebem a si. Cheirosos, melodiosos, ornamentais, seus corpos e transformações corporais neste mundo apontam para uma realidade espiritual, de outro mundo - a realidade do devir póstumo, da eterna renovação na morada celestial dos mortos (shoko nai shavaya). A realidade yové é performática, antropomórfica e, sem dúvida, sinestésica: sua latência nos seres humanos, sob a forma de alma direita mekiri vaká, tem inerência terrena.

A glosa "espírito", ou espiritualidade, pode evocar para muitos de nós a dicotomia corpo versus alma, a excluir de si qualquer corporalidade. Mas a realidade "outra" do yové, enquanto homúnculo, exclui tal dicotomia ao mesmo tempo em que sugere a dicotomia natural versus sobrenatural. Por sua vez, uma contraposição com os duplos yochi levaria à dicotomia humanidade versus animalidade... Peço ao leitor que tome minhas glosas com reservas. Aqui, "espírito" refere-se mais a spirare, respirar, do que a "espiritualidade"; e duplicidade se refere mais a ambigüidade do que a dicotomia.

Explico. Enquanto yochi é o duplo presente dos animais e também o duplo-animal pretérito e o duplo-animal futuro de seres humanos vivos e mortos, de sua alma esquerda mechmiri vaká, a epítome do espírito yové é o pássaro mawa, um auxiliar ocasional na cura, a contraparte da mekirí vaká humana, a alma direita que devém espiritual. Embora possamos glosar yochi como "duplo-animal" e yové como "espírito", esses diacríticos anímicos para as vaká corpóreas "esquerda" e "direita" têm 
muito em comum. Pois tanto yochí como yové são entes encontráveis no discurso xamânico; e neste ambos os entes são igualmente análogos a animais em primeira instância, embora não apenas à animalidade literal - mas também a seres humanos mortos e a xamãs vivos. A distinção binomial entre animalidade e espiritualidade dessas entidades tem mais a ver com psicofisiologia e escatologia - o que a pessoa é em relação ao que ela pode vir a ser. Depois da morte, enquanto a alma esquerda mechmirí vaká deixa-se ficar na terra, a alma direita mekiri vaká ascende ao céu.

Não há, porém, conformação possível de yochĩ e yové com a antinomia da esfera sublunar da geração e degeneração perante o âmbito eterno das idéias, como na hierarquia ontológica de Platão: as glosas "animal" e "espírito" não podem ser vistas como manifestas - as inflexões semânticas desses termos são temporais, presentes nas palavras e notas musicais dos cantos-mito -, as sucessivas linhas verbais e os círculos musicais reiterativos de sua poética.

Os cantos-mito saiti representam uma dualidade de entes transformantes na medida em que são inflexões latentes: as almas vaká do corpo yora são múltiplas e transformativas, embora o substrato delas seja uma integração individual. As almas e os corpos marubo mantêm entre si relações ambíguas - a saber, um conflito complementar que não é receptivo a nossos silogismos ordinários. Se as primeiras transcendem os últimos como um devir fatídico, todos são literalmente imanentes aos seres humanos, visto que as linhas circulares saiti, o antes e o depois mítico-musicais, ocorrem em todos os níveis da humana "consciência respirante" (chinã) - isto é, não como conceito, mas como performance: o líder-cantor xamânico e o coro genérico, o homem adulto e o aprendiz, jovens de ambos os sexos.

O tópico da transformabilidade da alma, vista enquanto irredutível a corpos invariantes, poderia de fato levar a amplas generalizações para 
Revista de Antropologia, São Paulo, USP, 2006, v. 49 no 1.

toda a Amazônia. Os corpos marubo na verdade mudam ao longo do tempo em resposta à dinâmica espaço-temporal das almas cósmicas ou como causa dessa dinâmica: há pouco espaço para teleologia aqui tanto dentro como fora dos seres humanos. Mas a definição de humanidade mais ampla e mais coletiva para esses povos, sua autodenominação etnonímica como - nawa, sua noção de ser de uma espécie, permanece distinta do corpo como tal, a saber, yora. Da mesma maneira que entre outros ameríndios, os Piaroa por exemplo (Overing, 1996), aqui "ser de uma espécie" representa o parentesco mais íntimo, mais sociável. Contudo, embora esses povos -nawa cultivem a sociabilidade, são eles epítomes duma perspectiva exógena, pilar da etnicidade indígena. Entre os Marubo, não é possível confundir alteridade com corporeidade diferencial. Aqui, contrariamente aos Matsigenka de Rosengren, a multiplicidade homogênea ganha um valor identitário positivo, embora essencialmente exógeno: simplificando, a palavra nawa sozinha, sem afixos, significa "estrangeiro". Eis o que ficou conhecido entre panólogos como "alteridade constituinte" (Erikson, 1986, 1996).

Entre os Marubo, todos os povos - nawa ganham nomes - nawa tomados de formas corporais como pássaros, plantas, coisas... todo tipo de animal. Entretanto, é dentro dos corpos yora em si que a latência de yové versus yochi de todas as almas indígenas possibilita a identificação entre homens e animais - o que nada mais é que um pré-requisito para a caça. Aqui, como em outras regiōes da América do Sul, é preciso seduzir a caça: seja chamando-a por termos de afinidade ou consangüinidade, seja atraindo-a para a situação predatória; um acordo ou pacto xamânico pode ser feito de antemão; seja como for, é imprescindível disfarçar a dessemelhança entre presa e predador, pelo menos enquanto atualidade para enfim reafirmá-la depois, no flagrante ato predatório. Além do mais, a intervenção xamânica pode tornar real uma identidade ontológica subliminar dentro dos ecossistemas cosmológicos, uma iden- 
tidade dada pela interseção de atributos comuns da alma que contradizem a variabilidade dos corpos. A tese segundo a qual as habilidades xamânicas na Amazônia, notadamente as cinegéticas, pressupõem que uma mesma alma é capaz de assumir formas corporais variáveis, ao invés dum mesmo corpo material comportar várias almas alheias, parece suficientemente válida entre os Marubo... desde que se assuma haver uma oposição manifesta entre corpos e almas. ${ }^{10}$

A premissa das distinçôes entre corpo e alma acaba por tolher uma comparação fascinante e promissora entre essas práticas xamânicas. É preciso profundidade em nível performático para tornar inteligíveis tais distinçôes percepto-conceituais entre corpos yora e entes anímicos como yochi e yové, mechmirí e mekirí vaká. Desde seu uso puramente lingüístico - yora com uma qualidade pronominal, na verdade um sujeito qualquer, "alguém", às vezes um marcador da identidade indígena - até a distinção mútua entre yochi e yové no reino animal e seus análogos mechmirí e mekirí vaká na psicofisiologia humana, todos esses termos têm mais relevância do que o procustiano corpo versus alma (ver Storrie, neste volume).

As relações que as almas humanas estabelecem e encenam nas sessões xamânicas e na linguagem ritual teriam mais afinidade com a condição corporal, sinestésica, à qual se chega por meio da manipulação de sensações, drogas, música e movimento - elementos que constituem todos os saiti. Por meio do saiti, o xamã alcança percepçóes sintônicas alternantes em face dos entes cósmicos, cuja pertinência para a esfera humana é tão real quanto essencial para a simples constituição dos corpos humanos. De fato, não apenas os xamãs - mas todos aqueles que participam ativamente dos festivais - adotam perspectivas corporais diferentes, isto é, eles transformam seus corpos atuando sobre eles e fazendo-os atuar, incorporando antes disposiçôes afetivas que almas diferentes. 
Revista de Antropologia, São Paulo, USP, 2006, v. 49 no 1.

Entretanto, para esses povos, corpos versus almas como transformações e transposições das diferenças entre natureza e cultura são relevantes na medida em que estas se revelam paradoxais - transitórias e, na qualidade de performance, temporais. Pois, ao invés de incorporar almas, os xamãs as excorporam por meio do som. Os Marubo dizem que, mediante convites musicais durante as sessões, os yovevo (plural de yové) vêm visitar o corpo do xamã, a morada das almas xamânicas, para fazer dele sua habitação transitória, como ocorre entre os Matsigenka de Rosengren. Contudo, será que isso significa que, durante essa troca espiritual, os corpos ficam vazios? Não, porquanto nem as almas dos xamãs nem os espíritos yové de fato "habitam" os corpos: o movimento deles em relação ao corpo yora é centrífugo, não centrípeto - já que se manifesta no cantar. A confluência das almas para dentro dos corpos é latente como uma tautologia pragmática, esquerda versus direita; corpos e almas se fundem como seres humanos e animais, como espíritos e duplos na atualidade da música. A música que os xamãs entoam é espiritual; é a atualização de uma identidade latente entre a alma direita, mekirí vaká, e o espírito yové. Essa expressão espiritual abarca, em células musicais reiterativas, a sucessão de versos verbais que narram a geração e a degeneração originais que o duplo-animal yochĩ representa.

O discurso xamânico extraordinário, a "linguagem espiritual" ou yové vana - música -, é a conseqüência, ou causa, de uma jornada exterior, ou antes uma projeção de vozes externas que são ao mesmo tempo carnais e anímicas. Os corpos marubo, ou pelo menos suas gargantas canoras kene môti (com belos, porém invisíveis, desenhos geométricos) que entoam yové vana, são ao mesmo tempo veículo e substrato. Entes anímicos animais e espirituais não ficam dentro dos corpos yora, mas aquém ou para além da conjunção original das almas corporais, como potencialidades possíveis. As almas marubo sempre se tornam reais por meio das 
cordas vocais corporais que vibram em simpatia musical quando sob o estímulo de uma voz yové exógena, espiritual e animal, sobrenatural e natural. Por isso, essas categorias qualificativas de "espiritual" e "animal" são estranhamente antinômicas, visto que os corpos yora, ainda que distintos em hemisférios anímicos, não soam em oposição a suas almas anatômicas constitutivas - a saber, mekirí e mechmirí vaká. A oposição pertinente jaz entre essas almas mesmas e em sua relação com entes cósmicos supra-humanos, extracorpóreos, os duplos yochi e os espíritos yové - ou entre seres humanos e animais, se preferir -, muito embora tal relação repouse numa oposição com um quê de aristotélico: em lugar de latência e atualidade, leia-se temporalidade. Os Marubo resistem ao tempo através do tempo: assim como suas almas são impermeáveis à idéia de oposição a seus corpos, também os xamãs e as práticas xamânicas são onipresentes e resistentes entre esses povos -nawa - para o fatalismo do missionário proselitista.

É por isso que o conhecimento indígena diz respeito ao saiti-e é de fato saiti e outras formas de canto -; e é por isso que tal conhecimento é redutível a essa ontologia musical, enquanto permanece irredutível a diferenciações em termos de substâncias corporais em contraste com formas anímicas, diferenciações estas que possibilitariam uma compilação enciclopédica e auto-suficiente de "conceitos-chave" em etnografia. Os cantos-mito saiti, em vez de serem designações abstratas de conteúdo semântico mais ou menos concreto, contêm significações imanentes como nas transcrições acima - que transcendem a significação designativa das palavras. Essas transcrições, que podemos chamar de "estruturas sônicas", são construtos heurísticos cujo propósito é ressaltar a inerência da verbalização e da musicalização do som. Para os Marubo, cantar significa ao mesmo tempo incorporar diferença e "excorporar" parecença com o mundo e dentro dele - isto é, com animais, plantas ou coisas, todos constitutivos etnonímicos - ao longo dum arcabouço temporal. 
Revista de Antropologia, São Paulo, USP, 2006, v. 49 no 1.

\section{Dualismo etnonímico}

A animalidade dual, a dualidade de alma da anatomia indígena e a conseqüente conexão de seres humanos com pássaros e animais, que no diaa-dia podem ser ou presas ou predadores dos Marubo, tornam-se reais na execução das histórias lineares dos saiti, em particular nas histórias que eles denominam "surgimento" ou "emergência" (wenia). Um saiti como Mokanawa Wenia, "o surgimento dos 'povos acre-selvagens" (isto é, povos da floresta), projeta o corpo-alma da futura humanidade emergente em duas formas animais - o espírito yové e o duplo yochi - ao longo de versos que se sucedem, do princípio ao fim, dentro de células musicais recorrentes. Em tais gêneses saiti, a criação dos seres humanos é coincidente com a criação desse par de entidades-alma que surgem menos como citações literais em palavras do que como melodias. Nos dizeres dos cantos-mito de emergência wenia, a humanidade surge antes duma identificação indireta, mas sucessiva, com aves e animais predatórios; ou seja, os povos emergem de substâncias originais da terra, as quais se associam a presas ou predadores, enquanto cada povo emergente mokanawa recebe primeiro seu nome e então sua língua em associação com um pássaro. O fato de yové e yochĩ , autoconstitutivos anímicos e anatômicos da humanidade, identificarem-se no canto-mito com cada animal prototípico é coerente com as associações que a onomástica estabelece - tanto nesses mesmos saiti quanto no dia-a-dia - entre o mundo dos Marubo e a palavra que entoam os Marubo: os animais etnonímicos são um protótipo primário de seres humanos como seres sociais, uma humanidade com nomes nawa.

Embora já bem conhecidos graças à literatura que trata dos Pano, esses nomes -nawa ainda pedem explicação. Tanto nos cantos-mito saiti quanto no dia-a-dia, pessoas marubo e seçōes de parentesco matrilateral em gerações alternantes ao nascer ganham nomes baseados em animais, 
plantas e coisas em geral: Shanenawa, Inonawa, Varinawa... Esses povos são os Pássaros Azuis-Verde (Shane), as Onças (Ino) e, dentre outras plantas e coisas, eles também são Sóis (Vari). São os povos -nawa. Eles concebem e mantêm a humanidade numa fenda: o eu é o protótipo do outro e vice-versa. O "outro" animal é o "eu" humano por meio de uma equação etnonímica: ao passo que os seres humanos ganham nomes de animais, os animais tornam-se paradigmas tanto da alteridade quanto da identidade graças ao status ambíguo de nawa - que é um sufixo, mas também pode ser uma palavra em si. Em lugar de ser uma categoria monovalente, "animal" é dual - exatamente como sua humanização em poética musical, dentro dos etnônimos nawa, contempla-o com uma latência dual, yochí e yové. ${ }^{11}$

Esse ponto merece mais esclarecimentos. Em alguns saiti, como o de Mokanawa Wenia, logo após a criação original dos seres humanos, os animais predadores, as presas e os pássaros que ajudam na constituição da humanidade (ao lado de plantas e outras coisas) equiparam-se a seres humanos no cotidiano por meio de nomes pessoais e etnônimos. $O$ fato de tais animais predadores e pássaros serem divisíveis em duas categorias (as que dizem respeito a pássaros yové e as que dizem respeito a predadores e presas yochĩ ), que não exaurem a variabilidade cotidiana de etnônimos (que incluem plantas e outras coisas) nem exaurem o tema da autoconstituição humana (a saber, a condição de ser nawa), sugere que predação e vocalidade não passam de atributos, embora essenciais, da humanidade - ambas seriam atribuiçôes que os seres humanos recebem de animais e de pássaros em sua constituição nawa. São atributos a predação e a vocalidade porque seres humanos adquirem a animalidade como potencialidades de alma - homens são homens graças apenas a um equilíbrio apropriado entre duas potencialidades animais dentro do seu corpo. Por conseguinte, aquelas categorias animais, yochi e yové, não são nem substanciais nem adjetivais para a humanidade, embora sejam 
Revista de Antropologia, São Paulo, USP, 2006, v. 49 no 1.

essenciais - sua essencialidade está no seu caráter nawa. Essas categorias não se inserem, em mútua exclusão, nos rígidos compartimentos de natural e sobrenatural. Graças ao lugar peculiar que a animalidade assume em tal ontologia, os status etnonímicos e antropogênicos dos animais colocam esses povos, mais uma vez, numa posição de resistência a universalidades conceituais.

Essas afirmações são apenas indícios daquilo que somente os cantosmito da criação, desenvolvimento que são de estruturas temporais, podem desvelar: isto é, em lugar de substância material, "mera matériaprima" ao estilo dos corpos chetsots dos Yanesha de Santos-Granero, os corpos yora, na qualidade de substratos, são a atualização subjetiva das almas feitas objetos potenciais, a subjetivação atual das potencialidades objetivas. A hipóstase animal dentro dos seres humanos é a contraparte lógica e transformacional da alma que materializa no exterior como doença yochí exógena e imoral ou como paradigma yové exosférico e moral - ou, ainda, como a contraparte-alma do etnônimo-animal. Isto é, as almas marubo são doenças-duplo ou auxiliares-espírito potenciais, e originalmente, do princípio ao fim, nomes -nawa - objetificaçôes potenciais de subjetividades supra-yora. $\mathrm{O}$ animal externo é, potencialmente, o equivalente corporal das almas humanas internas. Corpos yora são duplo-yochi e espírito-yové potenciais, ao passo que suas almas-vaká corpo-constitutivas não são uma essência exclusiva da humanidade: pelo contrário, almas da esquerda e da direita - que se manifestam como perceptos no olho (vero yoch $\hat{i}$ ) e excreçôes (isó yoch $\vec{i}$ e po $\hat{i}$ yoch $\hat{i}$, duplos da "urina" e das "fezes") em pensamentos-fôlego (chinã) e sombras (noke yochi - também são emblemas da não humanidade se tal distinção da esfera humana for de alguma forma pertinente.

Com efeito, enquanto a axionomia das entidades yochí e yové mantém correspondência variável com outras dicotomias ontológicas na Amazônia, ${ }^{12}$ o ponto em questão é que análises e analogias partindo de 
tais modelos categoriais como corpos versus almas, enquanto análogos analíticos à natureza versus cultura, não são de forma alguma pertinentes na estase: tais "duplos" e "espíritos" existem apenas como aspectos potenciais no interior e em relação a corpos yora, isto é, a seres humanos. A peculiaridade de tal oposição de valores é que os duplos yochi e os espíritos yové estão para além do corpo humano e ao mesmo tempo o constituem como potencialidades. ${ }^{13}$

Embora isso seja algo dado no saiti, não está perdido no passado mítico. Assim como para os Ayoreo de John Renshaw (neste volume), tal noção cronológica do mítico como algo remoto seria por si mesma um mito. Aquelas distinções anteriores - espírito yové e duplo yochi, pássaro e animal predatório, sujeitos e objetos, seres humanos e coisas no mundo - são elas mesmas a fundação recorrente da humanidade indígena. Esses povos -nawa são objeto de denominações culturais, isto é, são eles os próprios humanos yora, porquanto sua subjetividade se iguala temporariamente à subjetividade da natureza objetiva - animais, plantas, demais coisas. Os Marubo são povos do Pássaro Azul-Verde (Shanenawa), da Onça (Inonawa)... e do Sol (Varinawa): a criação humana é cosmogonia - de plantas, animais e demais coisas no mundo. A hipóstase da humanidade é, sobretudo, um estado somático de síntese sinfônica. ${ }^{14}$

Animais, plantas e demais coisas etnonímicas à parte, a equação que conjuga animais e seres humanos, "nós" e "outros", faz ainda mais sentido com referência a outra categoria de animal - nem pássaro, nem predador. Trata-se do porco-queixada (yawa), que vem, ritualmente, ao primeiro plano nas paródias em festas para celebrar e propiciar a caçada. Nessas festas saiti, cinegéticas e específicas, os porcos de mentira que os caçadores de mentira reúnem em bando são a presa arquetípica. A referência a esse animal alude ao mito de novo no canto saiti de Yawa Tivo. Entre seções de parentesco, o porco-queixada não é um animal emble- 
Revista de Antropologia, São Paulo, USP, 2006, v. 49 no 1.

mático para os seres humanos, porém é extremamente emblemático em caçadas - uma presa preferencial. ${ }^{15}$

A caça aos porcos é um evento social por excelência, pois reúne um grande número de pessoas de várias malocas vizinhas - homens, mulheres e também crianças. Essas expedições de caça servem para criar, consolidar e revelar laços de solidariedade na vida em família, especialmente entre jovens casais, que prefiguram um casamento feliz quando são vistos caçando juntos. Perseguir e matar esses bandos numerosos e perigosos exige uma estratégia coletiva; os frutos da caça são suficientes para um banquete, uma oportunidade para promover festivais. Da mesma maneira que nas demais festas saiti, a coreografia e os cantos saiti específicos dessa festa parecem uma pantomina simbólica em que homens, mulheres e crianças, alternadamente, representam os atores duma caçada ritual. Os porcos yawa, sua presa favorita, requerem uma identificação com seres humanos diferente daquela que ontologicamente existe entre a humanidade e a animalidade homônima por meio dos etnônimos, das dualidades da alma - dos cantos-mito saiti da criação wenia. Outra vez, é ao ouvir Yawa Tivo, mito-música que canta ao mesmo tempo a criação e a transformação, que essa identidade dessemelhante tende a fazer um sentido maior.

Se pássaros e predadores estabelecem relações com o homem -nawa como índices de nominação no mito e nos tratos diários, os homens estabelecem relações com os porcos na caça e no saiti de Yawa Tivo. As relaçóes entre o caçador humano e a presa arquetípica porco-queixada, que o festival saiti antecipa ao buscar boas graças na caça, tornam-se realidade durante a caça real. São relações de ancestralidade comum, como aquele saiti nos mostra: desta vez, ao invés de descrever os seres humanos emergindo da substância animal - como no surgimento wenia -, a mito-música mostra os porcos como transformações de seres humanos. Se os cantos-mito da criação wenia estabelecem associações 
constitutivas entre pássaros e animais de predação dum lado e seres humanos de outro, a humanidade ancestral dos porcos, no canto-mito Yawa Tivo, associa a presa ao predador humano. As presas-queixadas são entes humanos degenerados e corruptos, mas a moralidade dessa degeneração parece menos relevante: a associação moral entre homens e animais repousa mais claramente nos laços originais de parentesco. $\mathrm{O}$ saiti Yawa Tivo suscita associações de parentesco alternativas àquelas que outros cantos-mito estabelecem entre seres humanos e seus homônimos seccionais. Se na criação wenia a humanidade é o nawa arquetípico, transformação substancial de animais etnonímicos, os porcos, os yawa do saiti, são por sua vez tivo, uma maneira de indicar seu status especial com respeito à predação humana.

Assim como nawa, a palavra tivo também denota por si só "prototípico" e "grande"; não tem a mesma denotação "estrangeiro", mas sim uma conotação com sutil inflexão para o interior, seja por consangüinidade, seja por afinidade. A presa prototípica, o porco-tivo, não partilha da mesma natureza intrínseca dos seres humanos, do tipo "semelhança familiar", como seus homônimos animais partilham (ver Werlang, 2001). Se animais etnonímicos de alguma forma geram humanos, por meio de laços comuns de substância metonímica ou metafórica, alguns humanos, quando no mito, geram porcos-queixadas.

Tivo poderia ser o produto de um amálgama etimológico dos afixos nominal e plural $-t i+v o-$, e isso seria coerente com seu significado, "ampla” ou "largamente", em vários saiti. Mas, na prática mítico-musical, tivo se aplica somente a animais. A palavra qualificadora tem um significado central em pelo menos dois dos cinco cantos-mito mencionados - em Yawa Tivo, claro, e em teté teka. Neste último, o protagonista principal, o animal predatório original, o gavião gigante teté, leva o apelido de txai tivo, o inimigo afim da humanidade - parente por afinidade, pelo menos, para aqueles seres humanos que, na sua dimensão 
mito-música original, persistem em sua busca por uma morada na terra. No caso em tela, txai tivo denota algumas inflexões que partilham duma base conotativa comum. A frase significa literalmente "grande primoadversário", "parente prototípico por afinidade ou cunhado" - é um ente aparentado, mas também um “inimigo". Sua denotação imediata é aquela da grande ave de rapina teté, o protagonista do saiti; mais além, pode conotar "local de residência" e "morada prototípica". Em suma, o gaviāo teté na qualidade de txai tivo é o "primo-cruzado-da-maloca". Quando ele morre, atingido eufemisticamente (teka) pela humanidade original, inaugura a afinidade com base numa alegação anterior de consangüinidade - exatamente como a transformação dos porcos-queixadas, em Yawa Tivo, inaugura a predação humana sobre os animais. Noutras palavras, tivo significa "amplamente outro", com referência tanto ao gavião teté quanto ao porco yawa - ecoando assim a "alteridade constituinte". Mas tivo significa afinidade baseada na consangüinidade, exatamente o status que a predação deve ter, enquanto nawa é o inverso, seguindo o princípio da identidade baseada na diferença. Pois tivo é animal; nawa é humano.

\section{Dualismo ontológico}

Entre os Marubo, a distinção entre nawa e tivo é apenas mais um nível de significação girando em torno das noções de humanidade e animalidade. Dentro dum espírito de aversão às categorizaçôes explicitamente definidas - evitando assim essencialismos iminentes e com vistas a uma conclusão -, resumirei três pontos que têm relação estreita com uma possível elaboração indígena sobre nossos conceitos de corpo e alma.

Primeiro ponto: que o estado mítico de origem, duma humanidadeanimalidade comum, uma provável proposição universal na Amazônia, 
é um estado de mutabilidade transiente - um estado de inconstância temporária entre os Marubo. Se acompanharmos a forma de sua expressão e manifestação na poética saiti, na música e no movimento, observaremos que as características comuns a homens e animais vivem uma transmutabilidade que jaz entre aqueles campos ontológicos que se referem respectivamente a pássaros, e a predadores e presas, assim como a plantas e demais coisas. A condição humana é em si uma condição liminar, não apenas com relação a referências ocasionais no saiti à iniciação, nem aos cantos-mito somente: o destino humano é uma reencenação ritualística, ao longo da vida, na caça, na doença, na cura e, por fim, na morte e no limbo pós-morte, quando as almas ou bem se demoram na terra ou ascendem ao céu da renovação. Embora alguns saiti sejam prenhes de referências propiciatórias, possíveis remanescentes de rituais da fertilidade, a maioria das festas é genérica e periódica; saiti é uma condição geral, humana e social de crescimento, decadência e renovação. Aqui não há lugar para idéias eternas - pois o dualismo indígena não é bidimensional.

A transformabilidade mútua e comutável entre humanos e pássaros/ animais-outros é o que constitui a humanidade tanto no dia-a-dia de hoje quanto através do tempo mítico-musical. Essa cronologia diferencial subsiste por meio do som, operando a conjunção de sucessivas reminiscências pretéritas com um projeto reiterativo para o futuro. $\mathrm{O}$ modo com que os cantos-mito saiti expressam a questão possibilita uma hierarquia ontológica ou ordem cronológica entre aquelas inflexôes temporais: o movimento de vir-a-ser humano que os aspectos em comum da humanidade e substância animal implicam, embora musicalmente circular, é linear dentro de sua circundante dimensão verbal. No saiti da emergência wenia, os seres humanos surgem primeiro como uma síntese de animais predadores, e então adquirem a linguagem com os pássaros. A repetição circular por completo desse movimento durante a exe- 
Revista de Antropologia, São Paulo, USP, 2006, v. 49 no 1.

cução, por sua vez, cria seres humanos a partir de yochí e yové, tornando-os potencialidades yochi e yové - possibilidades de doença e saúde, destinos em potencial ao longo da vida e destinaçôes reais na morte. Em sua execução ao longo do tempo - incluindo gênese, vida e morte -, almas humanas vivas como constituintes de corpos yora são antes animais e depois espirituais, puras potencialidades para devirem sucessivamente na vida póstuma: após a morte, o caminho yochi cheio de transformações escatológicas, vei vai, precede a morada shoko nai shavaya da renovação yové, a morada cósmica que paira acima dessa "nossa terra", dessa "perigosa terra das transformaçôes" (nokê mai, vei mai shavaya). Tanto neste quanto noutro mundo, os espíritos yové são a periodicidade circular do fugidio, duplos yochi em sua linearidade descontínua. $\mathrm{Na}$ terra, a jornada escatológica ocorre no saiti Vei Vai Yoya, o canto-mito que faz as vezes de guia no perigoso caminho pós-morte - realizando, em forma mítico-musical, numa coreografia especial, essas transmutaçôes de formas vivas e mortais. Aqui o líder-cantor yoya conduz não só o canto-mito saiti como também os demais cantores, quando guia os dançarinos-cantores por uma linha sinuosa em lugar do círculo habitual. O saiti do vei vai é o yoya - o próprio guia é o canto-mito mesmo - e, assim como em tantos cantos-mito saiti, eis a ontologia indígena em suma: se vai significa "caminho", vei significa ao mesmo tempo os perigos da morte e das transformações no pós-vida.

Os Marubo oferecem uma segunda garantia - uma implicação - contra essencialismos categóricos acerca de relacionamentos entre homens e animais, premissas corpo versus alma e conseqüentes conceitualizaçóes na Amazônia: ao lado da variabilidade, a consubstancialidade das potencialidades da alma. Seguindo a discussão precedente, isso repousa num comentário nativo durante a tradução de mito-música. No saiti Yawa Tivo, os destinos dos porcos-queixadas transformativos diferenciam-se segundo a atitude predatória sensorial da humanidade de ori- 
gem em relação à presa anormal: os ovos do pássaro espiritual yové. O destino dos homens originais que passam por transformação depende de tais homens ou bem comerem os ovos do yawa chai, o pássaroporco, ou bem cheirarem simplesmente as cascas dos ovos - este emblema de elo filial. ${ }^{16}$ Alguns dos humanos ex-nawa transformados em porcos, ancestrais daqueles que hoje são presas dos seres humanos, permanecem nas florestas terrenas. Alguns porcos ficam às margens de rios estrangeiros, nos domínios do estrangeiro-nawa, e com isso se tornam porcos domésticos - os ocidentais não exibem etnônimos seccionais, da mesma maneira como os nomes seccionais indígenas não incluem um suposto yawanawa, "povos-filhos do porco-queixada": os brancos estão semanticamente mais próximos dos queixadas do que do Sol e do Pássaro Azul, da Onça e de outros seres e entes do mundo indígena. Por fim, alguns dos porcos gerados a partir de homens ascendem aos céusyové da regeneração.

No canto-mito Shane Memi Yôsha, um ser humano quase se transmuta em animal de caça, um duplo-yochi por excelência. Antes, porém, como acontece em tantos cantos míticos, a transmutação humana em outro ser segue o mesmo destino celestial das almas mortas semelhantes aos yové. Em Yawa Tivo, alguns dos homens que se transformam em animais ascendem à morada espiritual da renovação corporal shoko nai shavaya - ascendem com corpo e tudo, não como certa "essência espiritual do porco-queixada", visto que os espíritos yové são corpos. Por mais contraditório que possa parecer aos cartesianos, a identificação espiritual é substancial, como no antigo latim. Províncias ontológicas se sobrepõem quando uma alma xamânica ingere alimento espiritual yové, e desse modo se perde. Igualmente, os porcos transformativos certamente vão se regalar com as plantas saborosas do paraíso, como a velha e a anta no saiti acima. Assim como noutros lugares da Amazônia, comensalidade é consubstancialidade. Todos esses seres humanos feitos animais, 
Revista de Antropologia, São Paulo, USP, 2006, v. 49 no 1.

presas de humanos feitas de gente, em algum momento e de algum modo, transformam-se substancialmente em espíritos yové, exatamente como a mudança corpórea na iniciação xamânica significa vir-a-ser yové. No canto-mito Yawa Tivo, aqueles que morrem por ter provado ou cheirado o ovo fértil do pássaro-porco acabam congregando com criaturas espirituais - corpos ornamentais, cheirosos, sensuais.

Ainda no mesmo saiti, outros homens feitos porcos permanecem no domínio original nawa, às extensas margens do rio (noa mato) dessa morada humana terrena (mai shavaya) - e, por conseguinte, domesticam-se. Isso é mais um atributo de exterioridade do que de domesticação: porcos-queixadas são sempre selvagens; porcos estrangeiros são sempre domesticáveis. Neste caso, os Marubo originais, os povos nawa, tornaram-se verdadeiros estrangeiros nawa, verdadeiros outros, porquanto domésticos. Bem como ocorre com animais etnonímicos - pássaros e animais predadores -, os queixadas caem num domínio ambivalente, igualmente de alteridade e identidade. Contudo, o domínio relacional do porco yawa, da presa prototípica, é posterior àquele dos espíritos yové e dos animais-duplo, almas-com-corpos, o pássaro etnonímico seccional e predador ou presa. Os porcos-queixadas são uma categoria nawa genérica, não uma categorização indígena específica dos povos nawa. São tivo.

Este é o terceiro argumento que particulariza as idiossincrasias marubo contra os essencialismos amazônicos - argumento esse que implica outra referência à história, seja ela mítica ou não. Ao longo do tempo mítico e histórico, esses povos constroem gradualmente a noção nawa por meio dum movimento migratório, saindo dos vales dos grandes rios para as cabeceiras dos afluentes - um movimento geográfico paralelo à sua atitude para com o exterior, em direção aos limites de seus assentamentos e aos limites de seu mundo terrestre, em direção às suas fronteiras étnicas e cósmicas. Essa construção histórica do estrangeiro-nawa é 
paralela à origem mítica da predação-tivo humana. Os queixadas foram, em tempos remotos, povos nawa-Varĩ, Shanê, Inõ, Kanã e Chã், respectivamente, povos do Sol, do Pássaro Verde-Azul, da Onça, da AraraAmarela e do Pássaro Genérico -, para então se tornarem uma dentre três categorias: ou porcos-yové, "espirituais"; ou porcos-queixada do tipo comum, o animal de caça que se identifica com o duplo-animal yochi; ou ainda porcos domésticos, os nawa genéricos ocidentais. As três categorias de porcos ex-nawa - porcos espirituais, simples porcos-presas ou porcos estrangeiros-nawa - passam à existência numa atribuição mútua de valores diacríticos da humanidade, tanto cósmica quanto etnicamente. No canto-mito, a alteridade predatória acompanha a identidade preliminar, semelhante às açôes praticadas nos rituais de caça - em oposição à variabilidade de animal, planta ou coisa antropogênicos a gerar o eu indígena. Tal como ocorre no saiti Yawa Tivo - em que os seres humanos originais nawa migram para o domínio estrangeiro da nawa-dade ("estrangeiridade"), inaugurando dessa maneira a predação -, na história, os homens eram índios nawa, belicosos outros, e se tornaram Marubo - ou "mansos" como eles dizem, "domésticos" - quando encontraram os nawa brancos (ver Werlang, 2001). Essas noçôes de humanidade e animalidade são uma função da história - no mito e no cotidiano. ${ }^{17}$

\section{Contra ideologia}

A transformabilidade das almas humanas em estados de afecção semelhantes a animais, a ambigüidade substancial desses estados corporais anímicos em contraposição à predação e o paralelo entre predação e a substância ambígua da nawa-dade são questôes que têm algo em comum. Para além dessas três considerações, o fio condutor em questão o leitmotif subjacente e indisfarçável - é a hipótese duma generalidade 
Revista de Antropologia, São Paulo, USP, 2006, v. 49 no 1.

amazônica: atributos culturais virtuais abarcando o domínio natural num nível sobrenatural, onde corpos variáveis fragmentam uma constituição unificada de almas em perspectivas espécie-específicas. Tal poderia parecer explanatório no caso dos Marubo, caso esses povos não fossem tão resistentes a uma dicotomia alma-corpo universalizante como um dado atemporal e aespacial, ou como uma estrutura invariante. As hipóteses de neo-animismo, perspectivismo e seus desmembramentos exigem tantos ajustes práticos neste e em outros casos, que é de se perguntar se valeria a pena o engajamento no debate. A atenção à ontologia indígena exige obrigatoriamente a não subscrição a qualquer tipo de "ismo" modernista - assim minha mestra ensinou.

Seria mais seguro dar ênfase às idiossincrasias: neste planeta indígena, "natureza" é uma glosa incompleta para uma miríade de acontecimentos e relaçóes que só fazem sentido dentro de uma estrutura mais ampla que, no entanto, é tão imanente que é difícil distinguir o que está "acima”, o que é sobrenatural. O que nós distinguimos é a temporalidade: cronologia histórica e musicalidade mítica, e vice-versa. O que temos em termos de organização espacial entre esses povos está, primeiro, firme na forma temporal; segundo, essa forma encontra a sua voz na música, e essa música traduz a gênese humana, enquanto toda a ontogênese provém da antropogenia; terceiro, essa criação humana é um amálgama de modalidades de exterioridade.

Os entes yochí e yové que povoam o cosmos onde o ser e o vir-a-ser humanos se desenvolvem são eles mesmos agentes dessas teorias nativas. Esses duplos e espíritos organizam o mundo vivo e o mundo póstumo de acordo com os saiti - formas espaço-temporais auto-explicativas. É sob tal estrutura inteligível - a distinção básica entre yochĩ e yové, entre os constituintes paradigmáticos da pessoa humana e do cosmos que a percepção dual do que chamamos "natureza" existe, em algo que melhor seria se chamássemos "música”. Poderíamos também classificá- 
la numa esfera "metafísica", mais-do-que-natural. Mas mesmo isso exigiria que se excluísse de tal expressão musical qualquer traço de metafísica pós-socrática, fosse ela platônica, aristotélica ou judaico-cristã. Afinal, o que é a physis amazônica? As Musas podem responder - em música.

$\mathrm{Na}$ análise precedente, é no corpo humano que as disposições espirituais e de duplos-animais se conjugam em síntese, numa estrutura de alma universal; e, se essa síntese somática é analisável em saiti, a disjunção e subseqüente realização dos termos do saiti se efetivam na caça, na doença e na morte. Isso parece se encaixar bem noutros contextos regionais, onde a primazia cultural humana ou, se o leitor preferir, a realidade cultural dos homens deve passar por uma negociação simultânea, uma tarefa que pode ser xamânica e/ou predatória sob o exercício de diferentes agentes - xamãs e caçadores, espíritos e animais. A predação objetifica a presa real no ato predatório e atualiza sujeitos humanos, ao passo que xamãs subjetivizam predadores e presa. Mas, para os Marubo, os homens-nawa, os pássaros-yovés e os duplos-yochi $\mathrm{i}$ da animalidade predatória são os interlocutores dum diálogo musical. A base comum dessas partes confluentes - aquela que estabelece a humanidade - é o ponto de convergência da voz cantante entre os modos musicais yoch $\tilde{i} \mathrm{e}$ yové, as células melódicas e os versos circulares. É nos cantos-mito saiti que os protagonistas das arenas predatória e escatológica deste e doutro mundo tornam-se audíveis, daí visíveis e do nosso conhecimento. $\mathrm{O}$ discurso mítico-musical intersubjetivo no interior das malocas estabelece a humanidade; a voz humana é ao mesmo tempo autoconstituição e compartilhar cósmico, tal como o objeto-saiti a representa. 
Revista de Antropologia, São Paulo, USP, 2006, v. 49 no 1.

\section{De novo a mito-música}

Agora é possível concluir este ensaio com seu tema de abertura: a reprodução da dialética formal-musical dos cantos-mito saiti em seu nível poético-verbal.

Como eu disse acerca do canto-mito Shane Memi Yõsha, uma expressão idiomática corrente no saiti é a iki a nãa, ou a ikiao i ("assim falou..."). Como numa peça de teatro, as falas são atribuição duma terceira pessoa em relação à platéia - a terceira pessoa real -, a saber, um atributo de algum personagem ou do narrador no decorrer da história. Aquela frase musical mítica nada mais é do que a versão ritual duma fórmula frasal típica na linguagem cotidiana dos Marubo, yorã vana. Quando alguém diz iki, "eles [ele, ela] falaram" após qualquer declaração, a agência da elocução pertence a um terceiro, não importando quem falou. Se o xamã araweté é "como um rádio" (Viveiros de Castro, 1992, p. 224), se o xamã juruna "não passa de um porta-voz" (Stolze Lima, 1999, p. 119), o cantador marubo é tido como um gravador: seu canto é um playback duma narrativa exógena. Em lugar duma declaração universal da verdade, o xamã fornece declarações de várias vozes, uma polifonia verbal diacrônica. $\mathrm{O}$ xamã multiperceptivo é um mutante, um glifo - um corpo yora hiperbólico, na medida em que todos esses corpos dividem-se em modalidades anímicas contraditórias. Os xamãs enxergam múltiplas perspectivas e sentem múltiplos corpos unicamente porque podem exteriorizar a multivocalidade implícita nos seres humanos, e esse é um dom que vem dos espíritos pássaro-yové. Do ponto de vista do xamã estrábico, a linha está sempre fora de foco - ou melhor, excêntrica, torcida em espiral -, pois as linhas temporais que representam essa ontologia são antes auditivas que visuais. O privilégio auditivo já é um traço 
epistemológico familiar na Amazônia (ver Santos-Granero, neste volume). Talvez valha mesmo a pena aventar a hipótese de suas bases ontológicas serem musicais (cf. Seeger, 1987; Bastos, 1999).

As linhas musicais dos Marubo modulam o tempo - e conseqüentemente o espaço terrestre dos duplos yoch $\vec{i}$ - em curvas circulares e celestiais, as células rítmico-melódicas recorrentes e os versos do saiti. Não por acidente - peço desculpas ao leitor por mais jargão aristotélico -, os cantos saiti não apresentam estrutura linear ampla, claramente espacial, como o apresentaria a transcrição lingüística duma narrativa mítica. O saiti dos Marubo, e talvez grande parte da mitologia amazônica - tão tendente à redução a discursos lingüístico-estruturais -, é menos redutível a "mitemas" do que a "células musicais", exemplos dos quais são vistos acima. Se qualquer perspectiva discursiva unitária for perceptível apenas no nível verbal do mito, a unidade musical nos cantos-mito saiti será sempre redutível a nada mais que a mesma célula reiterativa - ou, no melhor dos casos, a grupos de células formulaicos ou verbalmente estróficos, que emulam a célula única. O fragmento reiterativo, o limite circular isolado, é uma fronteira poético-musical singular. Aquilo que é inefável na linguagem comum está inserto nas palavras do saiti pelo som do tempo mítico - pela expressão poético-musical.

As expressões vocais musicais e míticas, aquelas que estão sob a mesma categoria saiti, são mensagens cuja produção e compreensão primeira - o análogo auditivo das alegorias visuais de Platão (Cornford, 1983) - é sonora, e sempre da perspectiva duma ontologia centrífuga que abarca qualquer invenção humana como agência cósmica externa, já que rejeita sujeitos solipsísticos. A ontologia dos Marubo está, ao contrário, dentro do corpo yora, numa palavra - mas não ali apenas. A "animação" desse corpo é ao mesmo tempo espiritual e animal, de modos duais que diferem fundamentalmente dos nossos, visto que, entre estes povos - assim como entre os Piaroa e outros ameríndios 
Revista de Antropologia, São Paulo, USP, 2006, v. 49 no 1.

(Overing, 1996, 1997; Storrie, neste volume) -, não existe matéria carnal morta cuja vida seja em forma de alma. Para os Marubo, nami é a "carne" que se pode comer; ocasionalmente o nosso "corpo", que dificilmente se enquadra na noção de "corpo" como oposto a "alma". O curso da enfermidade, a ação dos agentes da enfermidade, por exemplo, se dá sobre o corpo nami; a ação do curandeiro se dá sobre o corpo yora; mas a efetivação da cura ocorre por meio da representação, invocação e articulação de entidades semelhantes a yochí e yové nos cantos de cura. Sem recobrar o equilíbrio justo, o fado do corpo yora é seguir seu destino pós-morte, que faríamos melhor em representar, invocar e articular como dissolução anímica do que como carnalidade vazia: nada resta para representar um "corpo-em-si-mesmo" depois que cada componente físico semelhante a alma atualiza seu destino desintegrativo, divergente - mekirí vaká e chinã, para o domínio celestial de rejuvenescimento como espíritos yové, e mekiri vaká e outras formas yochí, para o vagamundear sobre a terra como duplo. Pelo fato de a morte despojar o corpo yora de sua subjetividade suprapessoal, um cadáver é equivalente a algum objeto do morto, a seu ambiente. Duas ou três gerações atrás, os parentes em luto o queimariam e o comeriam, e talvez até ateassem fogo à maloca inteira com todos os pertences do morto. Pois um corpo morto é coisa nenhuma, é uma "não coisa": é espaço linear que, por si só, não pode alcançar a temporalidade circular dos espíritos musicais.

A estrutura que molda essas relações corpo-alma entre entidades como yora e nawa, yochí e yové, mechmirí e mekirí-vaká está no cerne da humanidade e do corpo humano, todavia, longe e fora deles. A cultura marubo não está em oposição ou posposição à natureza, pelo contrário: é uma condição original ao mesmo tempo atrás e para além dela, sobrenatural e subnatural. A humanidade marubo é representada e estabelecida, originada e prognosticada dentro desses dois domínios, que nos cantos-mito saiti entrelaçam-se num só. Humanidade é um "agora” que 
não é nem instantâneo nem o "zero" duma escala de tempo linear; é uma condição "corpórea”, mas também "espiritual”; uma condição "musical” - diriam esses povos, caso tivessem necessidade de expressá-la em palavras. Porém preferem entoá-las.

É verdade, esta é uma visão de mundo local. Mas de quem é esta visão se assumirmos o "ponto de vista dos nativos"? No que diz respeito aos Marubo, não podemos confiar em perspectivas visuais, porquanto não podemos opor o universal ao particular. Para esses povos, a cultura não é um atributo exclusivamente humano do qual a humanidade deveria estar fausticamente orgulhosa - seja em termos absolutos, seja em termos relativos. Embora seja preciso ficar com o pé atrás em relação ao vocabulário metafísico ocidental e às oposiçōes que este acarreta - por exemplo, a dicotomização a priori de sensações versus intelecto ou natural versus sobrenatural -, não se pode prescindir do diálogo etnográfico com tais dualidades e com aqueles que as invocam, mesmo se - mas somente se - essa posição nos levar a declaraçôes paradoxais. Se a condição humana é, entre os Marubo, um atributo cultural, é um atributo que existe por meio da incorporação e da "excorporação" temporais das afecções animais e espirituais, que escancara as portas da percepção ao mundo e lhe dá voz. O mundo marubo está em contínua tradução sinestésica... como se fora uma performance musical.

\section{Notas}

1 Para antecedentes etnográficos, ver Melatti (1977, 1981), Montagner Melatti (1985) e Werlang $(2000,2001)$.

2 Heidegger: "[...] subsiste, todavia, a necessidade de, nas diferentes etapas do caminho, falar justamente na linguagem que convém" (1990, p. 73).

3 Pedro Cesarino leva adiante uma pesquisa de doutoramento sobre mito e poética entre os mesmíssimos povos que figuram neste ensaio. 
4 Exceto pelas funções mais altas da alma - que prescindem de afeição, tal como o "motor imóvel" da Metafísica, de Aristóteles, uma versão antiga do Deus judaicocristão. Ver Aristóteles (1986).

5 Ver Viveiros de Castro (1999) e sua contribuição em Bird-David (1999).

6 Metonimicamente, shane significa também uma espécie de pássaro "azul-verde" (Cesarino diz azulão, conferindo uma inflexão "azulácea" à percepção indígena).

7 Cesarino disseca: a iki aoi = demonstrativo + intransitivo auxiliar "dizer" + novamente? - a locução pode ter uma inflexão inconclusiva, imediata.

8 A Missão das Novas Tribos está presente na área desde o início dos anos 1950.

9 'Poder-se-ia dizer que, em última análise, o 'espírito' das pessoas ou das coisas reduz-se a sua capacidade de serem lembradas e imaginadas após a percepção delas haver cessado" (Freud, 1999, p. 117).

10 Ver Descola (1994), Stolze Lima (1999) e Århem (1993), para explicações representativas da caça xamânica na Amazônia, Erikson (1996), para os povos pano, e Viveiros de Castro (1998), para uma síntese etnográfica.

11 O Vari de Varinawavo seria uma categoria residual, porém bem conspícua no saiti. É decerto plena de significado exógeno também, já que a associação entre o "Sol" e o "Inca" é um tema mitológico conspícuo entre os Pano, tal como entre os Kaxinawa (cf. Lagrou, 1998).

12 Como a "vida dos pensamentos" versus a "vida dos sentidos" dos Piaroa (Overing, especialmente 1988), e a yechoyeshem "sombra" versus yecamquën "vitalidade" dos Yanesha (Santos-Granero, neste volume).

13 Overing observa entre os Piaroa: "[...] a singularidade dos seres humanos terrenos deve-se à particular combinação de forças pela vida que eles hoje são capazes de conquistar" (1999, p. 10).

14 De novo Overing: "Pelo fato de os animais existirem eternamente no 'tempo de antes' [...], eles afetam os seres humanos terrenos de um modo literal" (1999, p. 12).

15 Embora Yawanawa seja um etnônimo real - de povos que vivem na vizinhança, no Acre, e que são parentes próximos dos Marubo -, aquele etnônimo é uma designação combinatória inaudita entre as seções matrilaterais dos Marubo. Para associaçôes históricas entre os dois povos, ver Coffaci de Lima (1994).

16 Em linguagem comum, vatxi significa tanto "ovo" como a saia tubular típica que as mulheres enlaçam na cintura. Os Marubo usam vatxi numa curiosa expressão 
para designar com precisão a sua origem natal: "lá onde deixei minha casca de ovo". Um invólucro genérico - a associação entre "ovo", "saia" e, digamos, "as capacidades reprodutivas femininas", ou simplesmente "o útero" ou "as páreas" conduz às origens humanas dos porcos-queixadas.

17 Compare com o sentido de domesticação para os Piaroa, igualmente "externalista", segundo Overing $(1988,1996)$.

\section{Bibliografia}

ÅRHEM, Kaj

1993

"Ecosofía Makuna", in CORREA, François (ed.), La selva humanizada: ecología alternativa en el trópico húmedo colombiano, Bogotá, ICA/FEN/CEREC, pp. 109-26.

\section{ARISTÓTELES}

1986 De anima (on the soul), trad. com introdução e notas de Hugh Lawson-Tancred, Londres, Penguin Books.

BASTOS, Rafael

"Apùap World Hearing: A Note on the Kamayurá Phono-Auditory System and on the Anthropological Concept of Culture", Antropologia em Primeira Mão 32, Florianópolis, Universidade Federal de Santa Catarina.

BIRD-DAVID, Nurit

1999 "Animism' Revisited: Personhood, Environment, and Relational Epistemology", Current Anthropology, vol. 40(Supplement): 67-91.

COFFACI DE LIMA, Edilene

1994 "Katukina, Yawanawa e Marubo: desencontros míticos e encontros históricos", Cadernos de Campo, vol. 4: 1-19.

CORNFORD, Francis M.

1983[1941] The Republic of Plato, Londres, Oxford University Press. 
DESCOLA, Philippe

1994

In the Society of Nature: A Native Ecology in Amazonia, Cambridge, Cambridge University Press.

ERIKSON, Philippe

1986 "Altérité, tatouage, et anthropophagie chez les Pano: la belliqueuse quête du soi", Journal de la Société des Américanistes, vol. 72: 185-210.

1996 La griffe des aïeux: marquage du corps et démarquages ethniques chez les Matis d'Amazonie, Paris, Peeters.

FREUD, Sigmund

1999[1913] Totem e tabu e outros trabalhos, Rio de Janeiro, Imago. [Trad. de Totem und Tabu: einige Übereinstimmungen im Seelenleben der Wilden und der Neurotiker, Leipzig, Hugo Heller.]

GEBHART-SAYER, Angelika

1985

"The Geometric Designs of the Shipibo-Conibo in Ritual Context", Journal of Latin American Lore, vol. 11(2): 143-75.

HEIDEGGER, Martin

1990[1977] A origem da obra de arte, Lisboa, Edições 70. [Trad. de Der Ursprung des Kunstwerks, Frankfurt Am Main, Vittorio Klostermann.]

LAGROU, Elsje

1998 Cashinahua Cosmovision: A Perspectival Approach to Identity and Alterity, tese de doutorado, Universidade de St. Andrews.

MELATTI, Julio Cezar

1977 "Estrutura social Marubo: um sistema australiano na Amazônia", Anuário Antropológico, vol. 76: 83-120.

1981 Povos indigenas no Brasil 5: Javari, São Paulo, CEDI.

1985 "A origem dos brancos no mito de Shoma Wetsa", Anuário Antropológico, vol. 84: 109-73.

1986 "Wenia: a origem mitológica da cultura Marubo", Série Antropologia 54, Brasília, Universidade de Brasília. 
"Soluções das culturas Pano para os enigmas do desenvolvimento corporal", in CORREAA, M. \& LARAIA, R. (ed.) Roberto Cardoso de Oliveira: homenagem, Campinas, Universidade de Campinas, pp. 143-66.

MONTAGNER MELATTI, Delvair

1985 O mundo dos espíritos: estudo etnográfico dos ritos de cura Marubo, tese de doutorado, Universidade de Brasília.

OVERING, Joanna

1985 "Introduction", in (ed.), Reason and Morality, Londres, Tavistock, pp. 1-28.

1986 "Men Control Women? The Catch-22 in Gender Analyses", International Journal of Moral and Social Studies, vol. 1(2): 125-56.

1988 "Personal Autonomy and the Domestication of the Self in Piaroa Society", in JAHODA, Gustav \& LEWIS, Ioan M. (ed.), Acquiring Culture: Cross Cultural Studies in Child Development, Londres, Croom Helm, pp. 169-92.

1996 "Under the Sky of the Domesticated: In Praise of the Everyday", ms.

1997 "The 'Conscious I', the Life of Desires, and the Attachment to Custom: A Piaroa Theory of Practice”, ms.

1999 "Puzzles of Alterity in an Amazonian Ontology: How is a God, Spirit, or Animal a Human Being from a Piaroa Point of View”, ms.

SEEGER, Anthony

1987 Why Suyá Sing: A Musical Anthropology of an Amazonian people, Cambridge, Cambridge University Press.

SOUSA, Eudoro de

1973

1975

Dioniso em Creta e outros ensaios: estudos de mitologia e filosofia da Grécia antiga, São Paulo, Duas Cidades.

Horizonte e complementaridade: ensaio sobre a relação entre mito e metafísica nos primeiros filósofos gregos, São Paulo, Duas Cidades.

STOLZE LIMA, Tânia

1999 "The Two and Its Many: Reflections on Perspectivism in a Tupi Cosmology", Ethnos, vol. 64(1): 107-31. 


\section{VIVEIROS DE CASTRO, Eduardo}

From the Enemy's Point of View: Humanity and Divinity in an Amazonian Society, Chicago, Chicago University Press.

1998 "Cosmological Deixis and Amerindian Perspectivism", Journal of the Royal Anthropological Institute, vol. 4(3): 469-88.

1999 "The Transformation of Objects into Subjects in Amerindian Ontologies", ms.

WAGNER, Roy

1981[1975] The Invention of Culture, Chicago, The University of Chicago Press.

WERLANG, Guilherme

2000 "Emerging Amazonian Peoples: Myth-chants", in HARVEY, G. \& RALLSMCLEOD, K. (ed.), Indigenous Religious Musics, Aldershot, Ashgate, pp. 167-82. Emerging Peoples: Marubo Myth-chants, tese de Doutorado, Universidade de St. Andrews. Mito-Música Marubo, ms. Marubo Musicality, Amazonian Musicology, ms.

ABSTRACT: The notions of "body" and "soul", within the dual universe of the Marubo from Southwestern Amazonia, intersect other contributions to this volume: firstly, in view of the present concern, from an universalizing perspective, on epistemological issues in Amazonia; and secondly, in view of a now ever-present relevance of indigenous ontology (here more as the "presentation", rather than the "investigation" or "account" of the origins of the cosmos and all forms of being therein) vis-à-vis the knowledge, with a particularizing tenure, of the performance of a cognitive ethos.

KEY-WORDS: Amazonia, Brasil, Marubo, personhood, cognition, indigenous ontology.

\section{Tradução de Telma Franco Diniz.}

Aceito em dezembro de 2005. 